\title{
Dialética e experiência
}

\author{
Franklin Leopoldo e Silva \\ Universidade de São Paulo
}

\begin{abstract}
resumo É bem conhecida a oposição estabelecida por Kant entre experiência possível e dialética, na medida em que esta última é caracterizada como a "lógica da ilusão". Ao mesmo tempo, o modo de pensar metafísico, que ocorre dialeticamente, em sentido kantiano, é uma tendência inevitável da razão, expressa na exigência formal de completude das categorias. Como o pensar, enquanto exercício livre da razão, é em si mesmo mais amplo do que a atividade de conhecer, própria do entendimento, o pensar contém 0 conhecimento, embora este se qualifique pelas regras e pelos limites determinantes da objetividade. A pergunta que tentaremos formular é se essa relação continente-conteúdo não poderia configurar também uma dependência da experiência em relação ao raciocínio dialético, que estaria de algum modo indicada na função reguladora das idéias da razão. Nesse caso, a oposição formal entre conhecer e pensar seria inseparável da inclusão estrutural (dependência) da experiência no âmbito da razão. Na raiz do problema estaria talvez a tensão (dialética) entre a aspiração subjetiva de totalidade e as exigências objetivas de limitação e segmentação da experiência e a forma da experiência teria de ser finalmente concebida a partir de um fundo de inteligibilidade problemática.
\end{abstract}

palavras-chave forma - ilusão - idéias reguladoras - objetividade

Pode-se caracterizar a dialética kantiana, enquanto exame da modalidade do pensamento de razão, como um prolongamento formal da analítica do entendimento. Como se sabe, em K ant a dialética se opõe ao entendimento assim como a ilusão se opõe à verdade, mas tanto no âmbito categorial quanto no domínio das idéias opera-se por meio da forma da R ecebido em janeiro de 2005. A ceito em maio de 2005. doispontos, Curitiba, São Carlos, vol. 2, n. 2, p.97-112, outubro, 2005 
análise. A análise é o procedimento comum, que do ponto de vista formal está presente tanto no trabalho de constituição da objetividade, em nível de entendimento, quanto na extrapolação por que a razão pretende atingir a completude do conhecimento, além da experiência possível. Poderíamos até mesmo dizer que a dialética aspira a um esgotamento da análise, na medida em que pretende chegar, de modo absoluto, à unidade, à totalidade e à identidade. Essa afirmação em princípio poderia suscitar a objeção de que o conhecimento objetivo para K ant é eminentemente sintético. De fato, sob o aspecto da sua efetuação, o conhecimento racional pretenderia realizar sínteses objetivas no plano da metafísica. Por outro lado, porém, é preciso lembrar que essa progressão na direção do incondicionado aspira a uma completude que tem como uma de suas significações fundamentais a possibilidade de extrair desse incondiciona do a série da qual ele seria o fundamento e, assim, estabelecer uma relação de identidade entre o princípio e a totalidade de suas conseqüências. $N$ ão nos esqueçamos de que o paradigma de metafísica presente no pensamento de Kant é de teor leibniziano, em que a análise é o método e 0 princípio de identidade, o fundamento em última instância. $\mathrm{N}$ esse sentido, pode-se dizer que se a ampliação do horizonte da síntese é meio de conhecer sempre mais, a finalidade do conhecimento metafísico é a plenitude analítica que seria a expressão epistemológica da identidade da substância, da totalidade das relações e da unidade que reúne todos os termos dessa totalidade. $E$ talvez não fosse demais afirmar, em continuidade, que a dialética enquanto conhecimento analítico expandido desempenha, como a análise leibniziana, a função de reduzir a multiplicidade à unidade e a diversidade à identidade, algo que já está presente nas categorias do entendimento entendidas como funções de unidade.

Embora essa significação metafísica da dialética não possa ser ignorada, a originalidade da filosofia crítica deve ser procurada na abordagem da significação transcendental da dialética. E não seria de menor interesse observar que é a reflexão crítica acerca da significação metafísica da razão dialética que nos encaminha para o esclarecimento da significação transcendental. A final, quando abordamos o uso transcendente das categorias do entendimento verificamos que tal uso é tão deletério ao conhedmento quanto necessário e inevitável para o pensamento. $\mathrm{E}$, ainda mais, vemos também que não há uma nítida precisão de limites, no plano procedi- 
mental, para que possamos definir com clareza a pertinência efetiva da generalização ascendente e da especificação descendente, isto é, a diferença entre a continuidade e a homogeneidade do ponto de vista da experiência e do ponto de vista lógico. Isso quer dizer que são os próprios objetos da experiência que nos encorajam a pensar uma unidade sistemática de uma diversidade que pode ser conhecida ordenadamente. É esse um argumento importante para que K ant possa passar da significação metafísica à significação transcendental no A pêndice à D ialética e vale reparar que tanto a possibilidade quanto a necessidade dessa passagem estão estreitamente vinculadas à impossibilidade de uma dedução das I déias, dada a ausência de condições do uso imanente. "0 que nestes princípios é digno de nota e também a única coisa que nos ocupa, é o fato de parecerem transcendentais e de, conquanto contenham simples idéias para se buscar o uso empírico da razão que podem ser seguidas por este apenas assintoticamente, isto é, só aproximativamente, apesar disso enquanto proposições sintéticas terem uma validade objetiva mas indeterminada, e de servirem como regra para a experiência possível, sendo além disso realmente usados com êxito como princípios heurísticos para a elaboração da experiência. $N$ ão obstante, não se pode chegar a efetuar uma dedução transcendental desses princípios, a qual é sempre impossível com respeito às idéias, como ficou provado acima" (KAN T, 1988, v. II, p. 158; B 691-692).

$\mathrm{N}$ ão havendo dedução transcendental, não se pode falar diretamente em princípios da experiência; como então Kant pode definir tais princípios como tendo "validade objetiva mas indeterminada" e como "regra para a experiência possível" ? Precisamente porque o estabelecimento da significação transcendental permite entendê-los como "princípios heurísticos para a elaboração da experiência". 0 u seja, é possível considerar um princípio da razão como uma regra da experiência se a utilização do princípio for, em primeiro lugar, objetivamente "indeterminada" e, em segundo lugar, se esse uso tiver caráter heurístico. A indeterminação objetiva da regra me permite vinculá la à experiência em geral e seu caráter heurístico permite que essa vinculação seja um uso heurístico na medida em que projeta a sistematização da experiência para além da unidade distributiva contida nas possibilidades categoriais. Por isso Kant define a idéia como um "analogon de um esquema da sensibilidade", tendo o 
cuidado de diferenciar o papel mediador desse esquema analógico da mediação do esquematismo: enquanto neste caso temos um esquema da síntese objetiva que se dá efetivamente, naquele temos um esquema da experiência em geral pensada como unidade sistemática. 0 analogon não se inscreve assim na efetuação do percurso determinante da síntese, mas permite que a objetividade das sínteses seja pensada no quadro de uma unidade sistemática de todo o conhecimento sintético possível. Há ao mesmo tempo indeterminação e validade objetiva porque no plano dos princípios o que é dado à razão é o "objeto na idéia" , o que não signifi$\mathrm{ca}$, do ponto de vista do entendimento, nenhum objeto, mas tão-somente o esquema de unidade sistemática em que se inserem os objetos, já que é necessário que se mantenha, em grau máximo, essa unidade sistemática "no uso empírico de nossa razão" (idem, p. 161; B 698).

“D esse modo, a idéia é propriamente só um conceito heurístico e não um conceito ostensivo, e indica não como um objeto é constituído, mas como, sob sua direção, devemos procurar a constituição e a conexão dos objetos da experiência em geral" (ibidem; B 699). U m objeto se constitui pelas condições de subsunção; tais condições não me fazem atingir a "conexão" dos objetos da experiência, porque esse é o plano da unidade da experiência em geral. Por outro lado, quando penso, pela idéia, uma tal conexão, não posso constituir objeto algum. N o entanto, não devemos por isso simplesmente opor constituição e conexão, embora se delimitem claramente como unidade categorial e unidade da I déia. Pois a definição da I déia como conceito heurístico nos leva a procurar tanto a conexão quanto a constituição. Talvez pudéssemos pensar que $K$ ant teria sido mais claro se tivesse separado as coisas, uma vez que já delimitara os âmbitos respectivos da constituição do objeto e da conexão da experiência em unidades sistemáticas. Por que então reunir problematicamente aquilo que parecia já estar tão bem separado?

Porque a Dialética é, em relação à finitude, um testemunho tão contundente quanto a A nalítica - e mais eloqüente que esta. $A$ delimitação da experiência a partir das possibilidades aferidas nas condições do conhecimento, conceitos e princípios do entendimento é uma análise da finitude. $M$ as não há que se contentar com o resultado dessa análise, isto é, com a positividade do conhecimento objetivo, estabelecida na limitação rigorosa da experiência possível. Pois o pendor natural da razão 
para transcender essa experiência está comprometido com uma busca de unidade e de totalidade que não ocorre segundo a divisão entre sensível e inteligível, imposta pela tradição, mas como uma ambição de ampliação de conhecimento que não distingue essa fronteira. Estaríamos aqui diante de um problema que vai muito além da diferenciação kantiana entre imanente e transcendente ou entre física e metafísica. Pois toda separação supõe antes a limitação das partes, mesmo que depois elas venham a ser integradas em uma totalidade. $N$ esse sentido, seria 0 caso de se perguntar se 0 dualismo platônico, arquétipo de todas as separações que se seguiram, já não confere ao pensamento uma limitação originária, por mais que afirme e valorize a possibilidade do conhecimento supra-sensível. Pois a própria transmutação do pensamento, necessária para transpor o limite, já compromete o pensamento do infinito com a esfera do finito que ele pretende abandonar ou mesmo negar. A mbigüidade admiravelmente presente em $D$ escartes, quando afirma ao mesmo tempo a prioridade ontológica do infinito e a anterioridade metodológica do sujeito finito.

O ra, a Dialética kantiana manifesta, em várias formulações, que se trata menos de pensar metafisicamente para além da experiência possível do que de abolir o sentido divisório desse possível, pensando a experiência de conhecimento e a hierarquia de seus objetos na continuidade expansiva de uma totalidade sistemática em que uma certa unidade originária reuniria todas as diferenças. E isso não estaria restrito ao que é examina do no capítulo referente à I déia Teológica, embora nesse caso fiquem ressaltados de modo mais claro os elementos primordiais do pensamento da unidade total e sistemática. 0 fato de pensarmos "algo" em "analogia com uma substância real", que venha a fundar toda a realidade e sua unidade necessária, é ainda uma particularização, em um ente metafísico, da totalidade una e sistemática, isto é, uma maneira de estabelecermos alguma correspondência entre a intencionalidade finita do interesse especulativo da razão e a realidade infinita. $M$ esmo a transcendência seria uma redução da infinitude à modalidade humana de visá-la. N esse sentido, a impossibilidade de continuarmos a conhecer objetos quando tenta mos ampliar o conhecimento é tanto perda da objetividade restrita do entendimento, quanto participação indeterminada da razão naquilo que está para além de todos os objetos. Essa ignorância de limites é vista por 
Kant como a perda de si por parte do sujeito cognoscente. $E$ a reafirmação do dualismo1 aparece então como a reposição da segurança: por isso em K ant essa reafirmação não significa apenas uma diferenciação entre o sensível e o supra-sensível, como no estilo platônico, mas a reconfiguração de toda relação de conhecimento segundo o domínio da subjetividade finita, o que afasta de vez a possibilidade de um "objeto" supra sensível, isto é, que seja visto como fora dessa relação, copernicanamente redefinida nos seus fundamentos.

0 que aparece aqui é a maneira como Kant se mantém fiel à impossibilidade constitutiva, historicamente configurada, de uma relação representativa com a totalidade na acepção de infinitude. E é por isso que Kant, sem abandonar as Idéias, faz que a significação transcendental prevaleça sobre a significação metafísica. 0 dualismo kantiano, ao definir a especificidade do conhecimento de razão, ao separar as condições transcendentais para melhor pensá-las na sua imanência à realidade empírica, salvando assim 0 objeto constituído na sua fenomenalidade, resguarda 0 alcance subjetivo da razão, demarcando-o fora da aplicabilidade objetiva, ou da determinação. Ao determinar 0 objeto nessa imanência, $K$ ant nega 0 objeto transcendente como conhecimento possível, sem ter de abandoná-lo inteiramente, porque a objetividade do entendimento não é a negação da razão, mas uma realocação do conhecimento racional que, ao mesmo tempo em que o mantém no lugar supra-sensível que ele tradicionalmente já ocupava, o destitui, a ele e a esse lugar, do valor cognitivo atribuído pela metafísica. R esta o valor heurístico, definido agora como regulador e transcendental, e resta um outro lugar, o pensar, distinto do conhecer. Assim se pode conceber uma expansão subjetiva da razão e uma delimitação definitiva do conhecimento objetivo. " $D$ e fato, a razão pura não está ocupada com nada mais senão consigo mesma, e não pode tampouco ter qualquer outro ofício, pois lhe são dados não os objetos para a unidade do conceito de experiência, mas os conceitos do entendimento para a unidade do conceito de razão, isto é, da interconexão em um princípio" (idem, p. 165; B 708). A unidade sistemática, não podendo incidir sobre objetos, singularizados na intuição empírica dos fenômenos, incide sobre conceitos e sistematiza os resultados do entendimento. $\mathrm{H}$ avendo assim um corte no procedimento de unificação sistemática, já que não se pode pôr em continuidade a unidade categorial e a unidade 
de razão, a amplitude desta última deve supor o "objeto na idéia" - e com isso Kant recupera a superioridade sistêmica da unidade racional nos termos do ens rationis, mas agora isolado, sem qualquer vínculo real com o conhecimento objetivo.

Em que pese a separação real, é preciso, segundo $K$ ant, que esse ente de razão seja pensado como fundamento de "toda a conexão de coisas no mundo dos sentidos", mas estando ele fora da experiência, essa dependência do fundado ao fundamento ocorre no plano do "como se". "[...] Isso ocorre unicamente com o propósito de fundar sobre ele [ente de razão] a unidade sistemática indispensável à razão [...] que promove sob todos os aspectos o conhecimento empírico do entendimento e não obstante jamais pode obstaculizá- lo" (ibidem; B 709). A unidade indispensável à razão tem que ser fundada além do entendimento, sem que por isso sua função deixe de ser a de promover o conhecimento empírico; o caráter absolutamente sistemático do fundamento não é obstáculo para a relatividade do conhecimento empírico. Esse "resultado" da Dialética ressalta ainda mais o que já deixamos implícito: a análise kantiana da finitude pode ocorrer por meio da exposição da funcionalidade do entendimento somente porque essa conclusão crítica está estreitamente relacionada à exposição do valor transcendental das I déias metafísicas. Q ual seja o teor dessa relação encontramo-lo na consideração que faz K ant sobre uma teologia transcendental. D epois de enfatizar a necessidade de se pensar a idéia de um ente que funde a unidade sistemática do mundo, diz K ant: "Com isso não se procurou pensar 0 que seja em si mesmo esse não-fundamento da unidade do mundo, mas antes como a sua idéia deve ser por nós utilizada relativamente ao uso sistemático da razão no tocante às coisas do mundo" (idem, p. 172; B 725; sem grifos no original). $\mathrm{N}$ a medida em que pensar o fundamento como o não-fundamento significa desconhecer o fundamento, 0 que a expressão sugere é um quesito de disciplina da razão, segundo o qual devemos ter algo como uma dupla representação do fundamento: pensá-lo a partir de sua necessidade inteligível e pensá-lo também a partir de sua impossibilidade em nível de conhecimento. A reafirmação copernicana do dualismo está totalmente voltada para justificar que aí não haveria qualquer incompatibilidade. Se a autonomia da razão significa a independência do transcendental, nada nos impede de pensar 


\section{4}

em um fundamento racional do conhecimento e das coisas que nos seja absolutamente inacessível como fundamento real do conhecimento e das coisas. Podemos e devemos admitir um fundamento último; não podemos, porém, alcançá-lo pelo conhecimento.

À luz dessas considerações, podemos talvez acrescentar algo ao que já foi dito acerca da questão da finitude. Sob a direção da I déia, diz K ant, devemos procurar a constituição e a conexão dos objetos da experiência. Essa busca é em si mesma mais ampla do que a admissão das Idéias. É provavelmente por isso que $K$ ant diz não apenas que devemos procurar a conexão dos objetos na experiência, isto é, a unidade total e sistemática, mas que devemos procurar também a constituição desses objetos. 0 ra, sabemos que, a partir das condições de síntese, 0 entendimento constitui a objetividade do objeto, portanto quando falamos em objeto no sentido de conhecimento (aquele que é relativo ao sujeito) podemos afirmar que 0 entendimento constitui o objeto e o resultado da dedução transcendental legitima essa afirmação porque nos mostra os meios de constituição da objetividade na efetuação das sínteses, em termos de intuição empírica e subsunção categorial. Em suma, podemos falar de constituição desde que tenhamos bem presente que nesse caso constituição equivale a subsunção e podemos, então, entender que procurar a constituição e a conexão na experiência significa produzir juízos sintéticos a priori. $M$ as a procura vai além, devido ao pendor da razão para a integralidade das condições; nesse sentido, em que a procura é pelo objeto na sua acepção mais geral e em que não há afecção do sujeito pela diversidade sensível, isto é, não há condições de subsunção, a constituição do objeto não pode mais ser a produção de sínteses cognitivas, mas a intuição intelectual pura. I sso vale para a constituição do objeto e para aquele aspecto estrutural ou sistêmico que devemos procurar, a conexão integral que nos permite atingir a totalidade. Essa visão intelectual do supra-sensível, a inteligibilidade da totalidade, é o oposto da produção da objetividade, na exata medida em que a intuição intelectual se opõe à discursividade do entendimento. É esse 0 aspecto em que a analítica da finitude e a delimitação crítica das possibilidades do conhecimento objetivo se sobrepõem em $\mathrm{K}$ ant, o que nos permite compreender porque a reafirmação da finitude deve assumir os traços de uma lógica transcendental, quando se trata de relacionar finitude e conhecimento. 
Vistas as coisas desse modo, seria permitido considerar a lógica transcendental, isto é, a analítica e a dialética, como uma teoria da experiência? $W$. $R$ öd, em um texto em que não se refere especificamente a Kant mas que 0 inclui certamente, define de maneira geral a dialética como a estrutura da relação sujeito-objeto que ocorre na modernidade, em que 0 conhecimento seria caracterizado pela reciprocidade desses elementos². Essa reciprocidade poderia, em princípio, ser aproximada da constituição da objetividade, de que falamos há pouco. Com efeito, somente há experiêndia quando se conjugam sinteticamente os dados sensíveis e 0 aparato transcendental do sujeito que deve apreendê-los. $\mathrm{N}$ em a diversidade sensível nem as formas da subjetividade transcendental poderiam, em si mesmas, fornecer conhecimento. Em algum sentido se pode, portanto, concordar com R öd: 0 objeto não é independente do sujeito nem 0 sujeito é independente do objeto. O s textos da A nalítica insistem nessa relação. $M$ as a reciprocidade talvez tenha de ser temperada pela prioridade do conhecimento de razão ou não atinaríamos com o sentido kantiano de a priori. 0 sujeito não existe independentemente do objeto quando o consideramos, por assim dizer, como operante, na sua função cognitiva. $\mathrm{N}$ o entanto, essa reciprocidade está inteiramente relacionada às condições de síntese cognitiva, que existem no sujeito de modo completamente independente dos conteúdos de experiência sensível. Essa estrutura a priori somente é produtora de objetividade quando relacionada a conteúdos sensíveis - e é dessa relação que surge propriamente o objeto no sentido especificamente kantiano, o que nos impede de falar em objeto sem a ação sintética do sujeito. 0 mesmo se dá em relação ao sujeito que, do ponto de vista lógico-transcendental, é a atividade sintética produtora do objeto - e nada mais. Essa reciprocidade necessária não deve impedir que reconheçamos o óbvio: a prioridade do a priori, da qual justamente depende a estrutura da experiência que, sendo de caráter lógico, não pode depender primordialmente do conteúdo. $\mathrm{N}$ ão é por outro motivo que a razão põe o objeto na I déia, pois nesse caso não há reciprocidade, mas apenas a estrutura formal, no âmbito puramente conceitual.

Entretanto, a observação de R öd permite também que consideremos de outra maneira a presença da dialética na estrutura da experiência e a possibilidade de que a levemos em conta em uma teoria kantiana da experiência. Explicando como Descartes retoma à sua maneira a 
distinção aristotélica entre a ordem do conhecimento e a ordem do ser, $R$ öd reitera aquilo que os comentadores de $D$ escartes assinalam como 0 duplo movimento das M editaçôes: "Segundo a ordem do conhecimento, 0 que vem primeiro é a experiência do finito; segundo a ordem do ser; contudo, 0 finito não poderia existir nem ser experimentado se 0 infinito não existisse e não fosse pensado" (R Ö D, 1977, p. 58). A experiência do finito não seria possível se não possuíssemos antes a idéia de infinito. Essa precedência do pensado sobre o experimentado produz uma conseqüência de grande alcance: tudo que possa ser determinado no âmbito de nossa experiência finita deriva da possibilidade humana de pensar o infinito. A diferença é que na esfera do finito podemos pensar e experimentar, enquanto 0 infinito somente pode ser pensado. A ssim, a experiência, e 0 que possamos pensar a seu respeito, permanece na dependência daquilo que unicamente pode ser pensado como inacessível a qualquer associação entre experiência e pensamento. $D$ onde se conclui que a experiência (e o pensamento a ela dimensionado) é uma limitação do pensar, que pode intencionar 0 infinito 3 .

A dialética estaria implicada na estrutura da experiência em K ant se pudéssemos mostrar que: 1) a categoria considerada no seu uso imanente seria uma limitação do princípio da razão e a dedução transcendental seria a exposição das condições lógicas pelas quais essa limitação ocorre como determinação e 2) correlativamente, a diferença entre pensar e conhecer deveria ser interpretada considerando-se o conhecimento como limitação determinada do pensar, o que daria ao conhecimento uma conotação negativa frente ao alcance do pensamento. De acordo com isso, na ordem da exposição da crítica, a Dialética deveria preceder a A nalítica. Podemos, em algum sentido, aceitar essas duas observações, desde que possamos também interferir na significação de termos-chave, como limitação e negação, ajustando assim a relação que se poderia eventualmente estabelecer entre Dialética e experiência.

1) Se pudéssemos - ou se devêssemos - atribuir aos conceitos puros do entendimento uma significação metafísica, então as categorias no seu uso imanente teriam de ser consideradas como aplicações restritas de princípios racionais e as condições de objetividade poderiam receber a denominação que está no texto de $\mathrm{R}$ öd: determinações limitativas. A significação transcendental inverte a perspectiva: como tanto o princípio 
da razão quanto a categoria do entendimento, enquanto formas, aplicamse a conteúdos, a questão passa a ser a das condições de aplicação: subsunção do dado empírico ou intuição intelectual do supra-sensível, visão do inteligível. A precedência da estrutura formal, que é a precedência do a priori, afinal, faz que as condições de aplicação somente se cumpram quando ocorre a produção da objetividade, nos termos da necessária presença da forma conceitualizante e do conteúdo a ser conceitualizado. $\mathrm{Na}$ hipótese de intuição intelectual não haveria produção de objeto, portanto não haveria aplicação da forma ao conteúdo, porque já estaríamos no nível do conceito em si mesmo, isto é, além do processo que envolve a forma conceitualizante e o conteúdo conceitualizado. Assim, mantendo a significação transcendental, o uso imanente das categorias não é uma determinação limitativa da Idéia porque, ainda que a categoria possa ser remetida à maior amplitude da I déia, ela possui um valor próprio que está dado na sua funcionalidade, na aplicação (no sentido de produção, visto acima) e que se identifica com seu caráter transcendental. C omo o transcendental é a estrutura funcional do conhecimento, os elementos transcendentais definem-se pela funcionalidade e, como o transcendental é lógica imanente, a funcionalidade, que é a imanência operacionalizada, aparece como primordial - e essa primazia só apresenta problema se não distinguimos bem a significação transcendental da significação metafísica. $N$ esse sentido é que dizemos que as categorias "tornam-se" I déias por via do postulado da integralidade das condições, mas não que as Idéias se tornariam categorias por meio de um procedimento de negação que as tornaria determinantes. I sso seria o mesmo que dizer que o indeterminado é a origem da determinação. $\mathrm{E}$ por isso também diz $\mathrm{K}$ ant que as idéias tornam-se dialéticas "por equívoco e imprudência" (KAN T, 1988, v. II, p. 165; B 708), isto é, pela confusão entre produção da objetividade e puro pensar.

2) A significação transcendental e a significação metafísica dos conceitos puros só podem coexistir se atribuirmos função cognitiva exclusivamente à significação transcendental. M antida essa distinção, não se pode dizer que uma seja a negação da outra. É por isso que, quando comparamos a vocação total izadora da I déia com as restrições da categoria no uso imanente, não precisamos considerar que a categoria aplicada à intuiçãao represente uma negação da I déia e que, portanto, a determi- 


\section{8}

nação se faça às custas da negação. Seria mais pertinente dizer que 0 uso transcendente da categoria é a negação da função categorial e, nesse caso, negação completa, porque não redunda em qualquer tipo de determinação. Ainda assim é preciso admitir que a dimensão do pensar é infinita mente mais vasta do que a esfera do conhecer e, nesse sentido, a determinação categorial é restritiva porque o campo da experiência possível não corresponde às possibilidades formais do conhecimento de razão pura. Assim, pode-se pensar a estrutura da experiência em dois níveis: primeiramente, 0 das possibilidades formais consideradas em si mesmas, caso em que as categorias possuem alcance indefinido; em segundo lugar, o nível das possibilidades formais de objetividade, caso em que 0 alcance das categorias é definido pela intuição sensível. Se houvesse uma separação completa entre esses dois níveis, a conseqüência seria a cisão da estrutura transcendental. Para que isso não ocorra e para que a estrutura transcendental possa ser inteiramente considerada uma estrutura da experiência, é preciso que, além da categoria em seu uso imanente, também a Idéia, em sua vocação totalizadora, se relacione com a experiência. Kant resolve essa questão por via da idéia reguladora, que assim desempenha, como idéia, aquela função que já vimos ser considerada por K ant como indispensável na estrutura do conhecimento, na medida em que essa experiência deve ser pensada, nas suas possibilidades estruturais, para além da segmentação distributiva das sínteses categoriais efetivas. A qui também a perspectiva transcendental inverte 0 que seria a significação metafísica: em vez de a categoria ser pensada como negação determinante da idéia, é a idéia que é vista como ampliação indeterminada da objetividade categorial, sendo que essa função da I déia, por ser reguladora, permanece no âmbito da significação transcendental. Essa incorporação da vocação totalizadora da razão à estrutura transcendental é necessária para retirar da I déia o caráter exclusivamente ilusório da entidade metafísica, fazendo que 0 uso regulador participe da efetuação do conhecimento, embora de maneira bem diversa do uso imanente. D esnecessário dizer que a legitimidade desses usos, ou de cada um deles, está estreitamente associada à reafirmação copernicana do dualismo, que dá ao sujeito transcendental a primazia na produção da objetividade.

Isso também pode permitir que se articulem duas exigências que configuram uma oposição, porque derivadas do pendor da razão para 0 
absoluto e das condições transcendentais do conhecimento objetivo. Com efeito, de um lado não se deve pensar dialeticamente; de outro, é inevitável pensar dialeticamente. A busca do incondicionado faz do pendor da razão uma exigência, sendo mesmo por esse motivo que a metafísica não pode ser eliminada do horizonte do pensamento. Entre 0 conhecimento objetivo da experiência possível e a integralidade racional como exigência de completude e totalidade Kant colocará, então, essa espécie de mediação lógico-estrutural, que é a função reguladora da I déia. Esse procedimento se justifica pelo fato de que a estrutura formal da experiência pode ser pensada para além das sínteses efetivas. $N$ ão há qualquer dependência constitutiva entre essas sínteses e as I déias reguladoras, mas pode-se estabelecer uma continuidade formal entre as exigências racionais e a experiência possível, o que é mesmo necessário para que a experiência apresente caráter sistemático. Essa inserção da possibilidade em um quadro de exigências que estão além dela não configura contradição, uma vez que 0 aparato transcendental que constitui a objetividade não está estritamente dimensionado pelo contorno da experiência possível. 0 que contribui também para esclarecer 0 sentido da procura pela constituição e pela conexão, de que fala Kant no A pêndice: como, desde a perspectiva da objetividade, as I déias são afetadas pela indeterminação, essa busca cumpre as exigências racionais sem redundar em extrapolação do uso imanente. É como se devêssemos ver aí não um procedimento, como nos casos das sínteses do entendimento, mas um processo, que extrai o seu sentido da impossibilidade de se completar como resultado cognitivo. Assim, a totalidade, dada como princípio regulador, no sentido de sua presença no horizonte da experiência, faz que essa experiência se construa visando à totalidade que ela nunca poderá constituir. Isso somente é possível porque as idéias desempenham função transcendental: enquanto independentes da experiência, prescrevem-Ihe, regulativamente, a sistematici dade na sua mais ampla acepção. $A$ totalidade deve ser construída na experiência porque ela é uma condição indeterminada dessa mesma experiência. 0 sujeito a procura porque já a possui. É dessa maneira que as I déias podem ser entendidas como fazendo parte da estrutura da experiência. Ao procurar constituir a totalidade, 0 sujeito constitui a experiência possível sob a égide da sistematicidade completa. Ao procurar constituir a totalidade das conexões, o sujeito encontra 0 


\section{0}

significado sistemático de cada uma daquelas que ele efetivamente constitui na experiência possível 4 .

Para que se admita uma estrutura da experiência é preciso supor que ela pode ser antecipada - e aí estão o significado e a função do a priori. M as o uso imanente suporia também um conteúdo dado, que também tem de ser antecipado como a generalidade do diverso captado pela intuição sensível. D ufrenne 5 chama atenção para isso: o conteúdo da diversidade em geral é antecipado como elemento a posteriori da experiência, submetido a condições estruturais. Essa pressuposição de realidade não nos faz voltar à questão da reciprocidade, como no caso de $\mathrm{R}$ öd, e pela mesma razão: não pode haver reciprocidade entre 0 a priori e 0 a posteriori. Se é lícito dizer que a realidade, em termos do conteúdo da afecção em geral, é estruturalmente pressuposta na concepção de experiência, isso somente pode significar a característica do transcendental, segundo a qual o uso imanente exige conteúdos dados. 0 que podemos aproveitar da observação de Dufrenne, para a questão que nos interessa, é algo um pouco diferente: ao contrário da sua afirmação, poderíamos dizer que a experiência particular pressupõe a experiência em geral para que 0 conhecimento objetivo possa ter sistematicidade. $E$ a experiência em geral pressupõe o princípio pelo qual podemos pensá-la na sua extensão máxima - na sua totalidade. Desse modo, a fundação da experiência possível pelo a priori, a que se refere $D$ ufrenne, inclui não apenas a categoria no seu uso imanente, mas também, e de modo "indispensável", os princípios que regulam a estrutura em termos de totalidade. Esta seria uma outra maneira de incluir os princípios da razão na estrutura da experiência, isto é, de entender que a D ialética dá continuidade ao exame crítico da experiência. Como assinala ainda D ufrenne, a questão é tanto a objetividade do objeto quanto a inteligibilidade da realidade, desde que essa afirmação de inteligibilidade não suponha a problematização do real no estilo do idealismo (DUFR EN N E, 1959, p. 36).

Se essa continuidade é verdadeira, sua razão de ser seria uma outra, a ser encontrada entre a aspiração subjetiva da totalidade e as exigências objetivas da experiência limitada. A contece que essa última continuidade é também uma tensão entre os mesmos aspectos e essa tensão faz que a inteligibilidade totalizante a partir da I déia seja considerada por Kant como problemática. $O$ ra, podemos então formular a questão que as consi- 
derações feitas até aqui tiveram o propósito de preparar: se a compreensão estrutural da experiência exige noções reguladoras que são princípios de indeterminação, e se há uma continuidade tensa entre tais princípiose a instância de determinação, não teríamos que compreender a experiência possível na sua forma estrutural, isto é, as figuras de objetividade, a partir desse fundo de inteligibilidade problemática?

${ }^{1}$ A reafirmação do dualismo entre sujeito e objeto é solidária, no plano das condições de conhecimento objetivo, da afirmação do dualismo entre entendimento e razão.

2 “Sin embargo, la moderna filosofía dialéctica no era en primera línea ontología o lógica, sino que se encuentro en el ámbito de la teoría de la experiencia con relaciones que podrían ser calificadas como dialécticas. Bajo el supuesto de que la experiencia se caracteriza como una relación entre sujeto y objeto, en la cual no puede hablarse ni de un objeto independiente de un sujeto, ni inversamente de un sujeto independiente de su referencia al objeto, se presenta la relación de sujeto y objeto como la de dos momentos que se condicionan recíprocamente dentro de la totalidad a la que pertenecen, y a la vez constituyen la totalidad de que son momentos" (R ÖD, 1977, p. 47).

3 “Este pensamiento - de que la formación de todos los conceptos determinados sólo puede lograr-se por determinación limitativa del absoluto - implica que en todo concepto determinado sea pensado consectariamente un momento negativo, pues su determinación debe consistir en que él no es absoluto. Spinoza, que hizo suyo este pensamiento, le dio la formulación que se ha hecho clásica: omnis determinatio est negatio, una fórmula que debía aprovechar H egel" (R Ö D, 1977, p. 58).

4 Goldmann destaca o modo de pensar a totalidade em Kant: um todo cujas partes, em termos de sua própria possi bilidade de existência, já supõem um conjunto sistematicamente conectado, de modo que a autonomia das partes se concilia plenamente com a exigência a priori do todo. Assim, a impossibilidade de realizar o todo não interferiria negativamente na efetividade das partes, regulativamente subordinadas ao princípio de totalidade. A Goldmann interessa o significado dessa relação entre partes e todo na construção da comunidade humana em $\mathrm{K}$ ant, mas entendemos que o encaminhamento ético, histórico e político de sua reflexão depende da compreensão da idéia de totalidade na DialéticaTranscendental. C f. Goldmann (1967, p. 60-70).

5 “L'expérience em géneral précède l'expérience particuliére, mas aussi la pressupose". N ão se trata de uma pressuposição ontológica, mas de uma realidade pressuposta. "Se réferer à l'expérience possible comme l'exige le transcendental, c'est finalement invoquer un donnée: l'expérience possible implique une expérience réelle. [...] Certes, si l'a priori se réfère à l'expérience, c'est toujours pour la fonder, et sans se subordonner à elle comme si elle le livrait. $M$ aisil a besoin delle autant qu'elle a besoin de lui, e ceci apparaît particulièrement dans les príncipes dynamiques où ' la synthèse s'applique à l'existence d'un phénomène en géneral, comme dit Kant" (DUFREN NE, 1959, p. 7-8).

doispontos, Curitiba, São Carlos, vol. 2, n. 2, p.97-112, outubro, 2005 
112

\section{Referências bibliográficas}

DUFR EN N E, M . 1959. La notion d'a priori. Paris: PU F.

GO LDM AN N , L. 1967. Introduction à la philosophie de K ant. Paris: Gallimard.

KAN T, I 1988. C rítica da razão pura. C oleção "O s pensadores". Trad. Valério R ohden e U do M oosburguer. São Paulo: N ova C ultural.

R Ö D,W. 1977. La filosofia dialética moderna. Pamplona: U niversidade de $\mathrm{N}$ avarra. 